\title{
Research on Price of Railway Freight Based on Low-Carbon Economy
}

\author{
Fenling Feng, Chengguang Liu, Haihong Liu, and Zhizhou Ji \\ School of Traffic and Transportation Engineering, Central South University, Changsha 410075, China \\ Correspondence should be addressed to Fenling Feng; ffl0731@163.com
}

Received 29 October 2015; Accepted 8 March 2016

Academic Editor: Yongjun Shen

Copyright ( 2016 Fenling Feng et al. This is an open access article distributed under the Creative Commons Attribution License, which permits unrestricted use, distribution, and reproduction in any medium, provided the original work is properly cited.

\begin{abstract}
Transportation is one of the major energy consumption and carbon emission industries. Railway transport is a typical low-carbon transport. To accelerate the green low-carbon transportation development and improve the railway market share, this paper defines the concept of carbon saving profit to study the price of railway freight after the government functions were separated from railway enterprise management. First, taking full account of market factors and on the principle of utility maximization and maximum likelihood method, the sharing ratio model of transportation modes is established. Then consideration is given to both the profit of railway enterprises and social benefits, and income maximization model of railway freight based on low-carbon economy is established. The model can scientifically guide the transportation users who prefer to use resource-saving and environmentalfriendly transportation modes, optimize transportation structure, and comprehensively improve the efficiency of transportation system. Finally, case analysis is conducted to verify the rationality and validity of the model, and reference for the rail freight pricing is provided.
\end{abstract}

\section{Introduction}

Climate change has become one of the most challenging issues the world is facing. Increasing number of countries have agreed that it is necessary to reduce energy consumption and $\mathrm{CO}_{2}$ emission. Transportation is one of the major energy consumption and carbon emission industries, emitting approximately one-quarter of the world's $\mathrm{CO}_{2}$ emissions in 2012 [1]; thereby transportation could take an important position in developing low-carbon economy. Railway transportation, a typical low-carbon transport, is a resource-saving and environmental-friendly transport mode.

Policy and decision makers have realized the importance of reducing $\mathrm{CO}_{2}$ emissions in formulating national economic and energy policies. "Promotional Guidance to Green Circulation and Low-Carbon Transportation" (number 323 [2013]) issued by the Ministry of Transport of China pointed out that transport structure should be optimized, the proportion of railway transport in the comprehensive transportation was raised, and transport energy consumption intensity was reduced. It also guides transportation enterprises to participate in domestic carbon emissions trade and so on. Obviously, carbon emissions have been gradually transformed from a pure environmental issue to an economic issue. The tariff is a key factor influencing the consignors' choice. Therefore, the focus of this study is how to utilize price lever to make consignors prefer to use a resource-saving and environmental-friendly mode of transport actively and scientifically.

From a global perspective, transport policy reform generally has experienced the change course from government regulation to enterprises' independent pricing at a certain extent. Deregulation of the transportation industry is attracting more and more scholars to join in the study of transport pricing. At the beginning of the study, the focus is on the enterprise level. The commonly used methods are cost-oriented pricing, return on investment and target profit, and so forth [2]. These studies are conducted mainly from the perspective of the supply side, ignoring the market supply and demand conditions and a variety of market factors. With the development of comprehensive transportation system, many scholars study from the angle of the transportation system and even the whole society, considering the competition and cooperation relationship between the modes of transportation [3]. He 
and Guo [4] proposed a pricing model of competition countermeasure on price and time in transport. The model can be used for making competition countermeasure among different transport ways. Chen and Luo [5] studied the dynamic competition of urban railway transport with routine public transit through using logit model and the game-theory of the competition behavior in economics and found that the optimum admission fee should be given up to seek the reasonable ticket price that can guarantee the income of the urban railway. Feng et al. [6] analyzed the Railway Geographic Network Topological Structure of China. Chi and Baek [7] studied the price and income elasticities of demand for air transportation in the US through using the data between 1996 and 2010. Results show that US airfreight industry is elastic in price and income aspects. Shah and Brueckner [8] developed a simple analytical model of price and frequency competition in freight transportation. Freight carriers maximize profit by setting prices, frequencies, and vehicle carrying capacities.

With the furious competition in transportation market, there are also some related studies about mode choice behavior. Samimi et al. [9] examined the way that truck and rail compete for commodity movement in the US and found that shipping cost is a central factor for rail shipments, while road shipments are more sensitive to haul time. Cullinane and Toy [10] and Wang et al. [11, 12] analyzed the major attributes which influence the consignors' choice. Usually, discrete choice analysis regarding a transportation system is based on random utility theory [13]. Rich et al. [14] used logit model to study choice behavior of freight transport mode.

In recent years, environmental problems have become the focus of attention. Researchers began to notice the negative externalities brought by the transport. In order to maximize the benefits of both travelers and operators and minimize the environmental cost, Sun et al. [15] built a bilevel model which takes travel time, operation cost, energy consumption, pollutant emission, and traffic efficiency as the optimization objectives. Lu et al. [16] built an optimal allocation model of public transit mode proportion (MPMP) to achieve the low-carbon public transit. Yin et al. [17] established a bilevel goal programming model for designing a financially and environmentally sustainable transportation system. Chao [18] presented a set of models that calculate carbon emissions in individual phase of flight during air cargo transportation. Yang and Xi [19] established a quantification model of freeway externality which can show the influence of freeway on sustainable development of social economy through resource and ecoenvironment.

To sum up, the researches of the scholars are mainly on highway and air transportation, and there is lack of railway pricing researches. What is more, few studies have developed to compensate for the impact of negative externalities caused by transport through the price. So it is greatly significant to study railway freight prices based on low-carbon economy.

\section{Modeling}

2.1. Sharing Ratio Model of Transportation Modes. The competitive relation between every type of transportation is reflected by their market share which is further related to the competitive strategies the transportation enterprises apply. Thus, the market share of transportation mode $i$ can be expressed as

$$
\operatorname{Pr}_{i}=f\left(V_{i}\right)
$$

where $\operatorname{Pr}_{i}$ stands for the market share of transportation mode $i$ and $V_{i}$ stands for the utility value of transportation mode $i$. If the transportation enterprise applies the competitive strategy of freight fare and service, then $V_{i}$ can be defined as

$$
V_{i}=f\left(P_{i}, F_{i}\right) \text {, }
$$

where $P_{i}$ stands for the freight fare strategy of mode $i$ and $F_{i}$ stands for the service level strategy of mode $i$.

\subsubsection{Model Assumptions}

Hypothesis 1. In a certain period of time, there are $N$ modes $(i=1,2, \ldots, N)$ of parallel transportation available to the consignor in the freight channel.

Hypothesis 2. The consignors are rational economic men. Namely, under a certain social and economic condition, they tend to choose the most profitable mode of transportation.

Hypothesis 3. The utility value of transportation is related to the freight fare and service. It decreases as the freight fare goes up and increases when the service improves.

2.1.2. Model Building and Solution. Service level shows different transportation modes' satisfaction degrees to the needs of cargo owners. It directly influences consignors' choice and further decides the competitiveness of a certain transportation mode in the channel. This paper chooses safety, timeliness, punctuality, and convenience as the four factors influencing competitiveness to analyze. $S_{i}$ stands for safety, which can be reflected by the rate of damaged goods; $T_{i}$ stands for timeliness, which can be reflected by the average traveling speed; $Z_{i}$ stands for punctuality, which can be reflected by the on-schedule rate, and $C_{i}$ stands for convenience, which can be reflected by the availability of transport service and transaction efficiency of the transportation mode. Therefore, the function $F_{i}$ of service level can be expressed as [20]

$$
\begin{aligned}
F_{i}=\lambda_{1} \omega_{1} S_{i}+\lambda_{2} \omega_{2} T_{i}+\lambda_{3} \omega_{3} C_{i}+\lambda_{4} \omega_{4} Z_{i}, \\
\\
i=1,2, \ldots, N
\end{aligned}
$$

$$
\text { s.t. } \quad \sum_{i=1}^{4} \lambda_{i}=1, \quad \lambda_{i} \geq 0, \omega_{i}>0,
$$

where $\lambda_{i}(i=1,2,3,4)$ stands for the weight coefficient of the four factors that influence the service level of transportation mode and $\omega_{i}(i=1,2,3,4)$ stands for the model parameter which serves to convert the dimension. This paper applies two different types of nondimensionalized standard functions to deal with the two different situations: when service level increases, the index value decreases, and when service level goes up, the index value goes up as well. The specific process is as follows. 
For the first situation (the smaller the index value, the higher the service level), the nondimensionalized standard function is

$$
\begin{aligned}
r_{i} & =u\left(x_{i}\right)=\frac{x_{\min }}{x_{i}}, \\
x_{\min } & \leq x_{i} \leq x_{\max } .
\end{aligned}
$$

For the second situation (the higher the index value, the higher the service level), the nondimensionalized standard function is

$$
\begin{gathered}
r_{i}=u\left(x_{i}\right)=\frac{x_{i}}{x_{\max }}, \\
x_{\min } \leq x_{i} \leq x_{\max } .
\end{gathered}
$$

For the service quality indicators above, the smaller the rate of damaged goods, the higher the service level, so $S_{i}$ is processed by formula (4). The rest of the indicators $T_{i}, Z_{i}$, and $C_{i}$ belong to the second situation (the higher the index value, the higher the service level), so $T_{i}, Z_{i}, C_{i}$ is processed by formula (5).

According to the characteristics of demand curve in economics, the freight fare and service level go up and the slope of demand curve decreases. So this paper uses exponential function to define the utility function of transportation modes. Therefore, the relation between utility value $V_{i}$, freight fare $P_{i}$, and service level $F_{i}$ of a certain transportation mode can be expressed as

$$
V_{i}=\theta_{1}\left(\frac{P_{\min }}{P_{i}}\right)^{1 / 2}+\theta_{2} F_{i}^{1 / 2},
$$

where $\theta_{i}(i=1,2)$ stands for model parameter, which can be obtained through the maximum likelihood method.

According to the Discrete Choice Model based on random utility theory, the random utility of consignor choosing transportation mode $i$ can be defined as

$$
U_{i}=V_{i}+\varepsilon_{i}, \quad i=1,2, \ldots, N,
$$

where $\varepsilon_{i}$ represents stochastic item.

Assume that stochastic item $\varepsilon_{i}$ is mutually independent and complies with the Gumbel distribution; then the competitiveness model of transportation mode can be indicated by the traffic flow distribution model of polynomial logit; namely, the probability of transportation mode $i$ being chosen is

$$
\operatorname{Pr}_{i}=\frac{e^{\theta_{1}\left(P_{\min } / P_{i}\right)^{1 / 2}+\theta_{2} F_{i}^{1 / 2}}}{\sum_{j=1}^{N} e^{\theta_{1}\left(P_{\min } / P_{j}\right)^{1 / 2}+\theta_{2} F_{j}^{1 / 2}}} .
$$

Then, in order to determine the value of model parameter $\theta_{i}(i=1,2)$, the likelihood function is built. $K$ stands for the sample size, $N$ stands for the number of transportation modes, and $\operatorname{Pr}_{i}^{k}$ stands for the probability of consignor $k$ choosing transportation mode $i$. Therefore, the joint probability function of sample can be expressed as

$$
L(k, \theta)=\prod_{k=1}^{K} \operatorname{Pr}_{i}^{k}, \quad i=1,2, \ldots, N .
$$

The maximum likelihood theory is to determine the estimated value $\hat{\theta}$ of parameters, so the sample's likelihood function (joint probability function) can reach the maximum value; namely,

$$
L(k, \widehat{\theta})=\max L(k, \theta) .
$$

Since $L(k, \theta)$ and $\ln L(k, \theta)$ reach extremum values at the same point, the natural logarithms on the two sides of (9) are taken, and partial derivatives $\theta_{1}, \theta_{2}$ are calculated. In this case, it can be obtained that

$$
\begin{aligned}
& \frac{\partial \ln L(k, \theta)}{\partial \theta_{1}}=0, \\
& \frac{\partial \ln L(k, \theta)}{\partial \theta_{2}}=0 .
\end{aligned}
$$

The solution $\left(\widehat{\theta_{1}}, \widehat{\theta_{2}}\right)$ of this equation set is the maximum likelihood estimated value of the model parameters.

\subsection{Income Maximization Model of Railway Freight Based on Low-Carbon Economy}

2.2.1. Model Building. First we define the concept of carbon saving profit. If one transportation mode saves a certain amount of carbon compared to another mode when delivering one ton of goods per kilometer, then we time this amount with the carbon trading price, and the value we get is called carbon saving profit.

Since railway is a typical low-carbon transportation mode, it is advantageous over other transportation modes in terms of carbon competition. So, in carbon emission trade, railway enterprises can gain profits through selling surplus carbon quota. From this perspective, carbon saving profits can be seen as the income of railway enterprises.

After being separated from the government, China Railways Corporation is in heavy debt and deficit. Railway freight income is the main resource of railway enterprises' total income. Therefore, this paper, holding the goal of maximizing railway freight income and taking environment into consideration, comes up with the carbon saving profit coefficient. I stands for the railway freight income which can be expressed as

$$
\begin{aligned}
& \max \quad I=\left(P_{i}+P_{c}\right) Q \frac{e^{\theta_{1}\left(P_{\min } / P_{i}\right)^{1 / 2}+\theta_{2} F_{i}^{1 / 2}}}{\sum_{j=1}^{N} e^{\theta_{1}\left(P_{\min } / P_{j}\right)^{1 / 2}+\theta_{2} F_{j}^{1 / 2}}} \\
& \text { s.t. } \quad Q \frac{e^{\theta_{1}\left(P_{\min } / P_{i}\right)^{1 / 2}+\theta_{2} F_{i}{ }^{1 / 2}}}{\sum_{j=1}^{N} e^{\theta_{1}\left(P_{\min } / P_{j}\right)^{1 / 2}+\theta_{2} F_{j}{ }^{1 / 2}}} \leq Q_{r} \\
& \\
& P_{\min } \leq P_{i} \leq P_{\max },
\end{aligned}
$$

where $P_{c}$ represents the carbon saving profit; $Q$ stands for the total freight demand within a certain period of time, $Q_{r}$ stands for maximum freight volume the railway can withstand within a certain period of time, $P_{\min }$ stands for the freight cost, and $P_{\max }$ stands for the highest price set by government. 


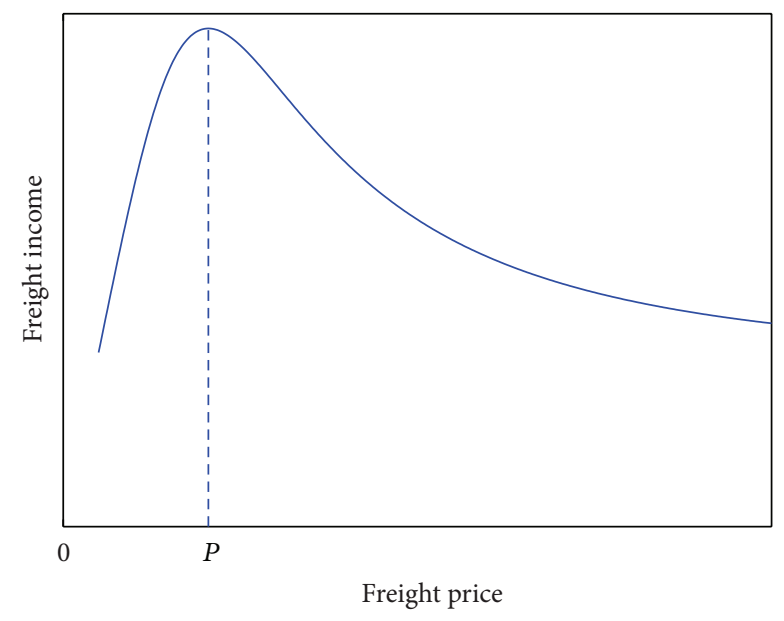

Figure 1: The relationship between railway freight income and freight price.

\subsubsection{Model Solution and Analysis}

Situation 1. When the carbon saving profit is taken into consideration, the target function can be expressed as

$$
\max I_{1}=\left(P_{1}+P_{c}\right) Q \frac{e^{\theta_{1}\left(P_{\min } / P_{1}\right)^{1 / 2}+\theta_{2} F_{1}^{1 / 2}}}{\sum_{j=1}^{N} e^{\theta_{1}\left(P_{\min } / P_{j}\right)^{1 / 2}+\theta_{2} F_{j}^{1 / 2}}} .
$$

Situation 2. If the carbon saving profit is not taken into consideration, the target function can be expressed as

$$
\begin{aligned}
& \max I_{2} \\
& =P_{1}^{*} Q \frac{e^{\theta_{1}\left(P_{\min } / P_{1}^{*}\right)^{1 / 2}+\theta_{2} F_{1}{ }^{1 / 2}}}{e^{\theta_{1}\left(P_{\min } / P_{1}^{*}\right)^{1 / 2}+\theta_{2} F_{1}^{1 / 2}}+\sum_{j=2}^{N} e^{\theta_{1}\left(P_{\min } / P_{j}\right)^{1 / 2}+\theta_{2} F_{j}^{1 / 2}}} .
\end{aligned}
$$

In function (13) and (14), the $P_{1}, P_{1}^{*}$ are railway freight fares to be obtained. If the freight fare and service level of other transportation modes are known, the railway freight fare can be determined according to the railway service level. Function (13) and (14) can be further simplified to be

$$
\begin{aligned}
& \max I_{1}=\left(P_{1}+P_{c}\right) Q \frac{h_{1} e^{\theta_{1}\left(P_{\min } / P_{1}\right)^{1 / 2}}}{h_{1} e^{\theta_{1}\left(P_{\min } / P_{1}\right)^{1 / 2}}+h_{2}}, \\
& \max I_{2}=P_{1}^{*} Q \frac{h_{1} e^{\theta_{1}\left(P_{\min } / P_{1}^{*}\right)^{1 / 2}}}{h_{1} e^{\theta_{1}\left(P_{\min } / P_{1}^{*}\right)^{1 / 2}}+h_{2}} .
\end{aligned}
$$

In function (15), $h_{1}$ and $h_{2}$ are known constants:

$$
\begin{aligned}
& h_{1}=e^{\theta_{2} F_{1}{ }^{1 / 2}}>0, \\
& h_{2}=\sum_{j=2}^{N} e^{\theta_{1}\left(P_{\min } / P_{j}\right)^{1 / 2}+\theta_{2} F_{j}{ }^{1 / 2}}>0 .
\end{aligned}
$$

According to function (15), we can draw a chart to describe the relationship between railway freight income and freight fare (see Figure 1). From Figure 1, we can know that, before the point $P$, the freight income is monotonically increasing; after the point $P$, the freight income is monotonically decreasing. The freight income reaches the maximum value at the point $P$. Therefore, $P$ is the railway freight price we are searching for.

To further compare the points $P$ of function (15), we take the derivatives of $P_{1}, P_{1}^{*}$ in the two equations and get the following equations:

$$
\begin{aligned}
& Q \frac{h_{1} e^{\theta_{1}\left(P_{\min } / P_{1}\right)^{1 / 2}}}{h_{1} e^{\theta_{1}\left(P_{\min } / P_{1}\right)^{1 / 2}}+h_{2}} \\
& \quad+\left(P_{1}+P_{c}\right) Q \frac{(-1 / 2) h_{1} h_{2} \theta_{1} P_{\min }^{1 / 2} P_{1}^{-3 / 2} e^{\theta_{1}\left(P_{\min } / P_{1}\right)^{1 / 2}}}{\left(h_{1} e^{\theta_{1}\left(P_{\min } / P_{1}\right)^{1 / 2}}+h_{2}\right)^{2}} \\
& \quad=0 \\
& Q \frac{h_{1} e^{\theta_{1}\left(P_{\min } / P_{1}^{*}\right)^{1 / 2}}}{h_{1} e^{\theta_{1}\left(P_{\min } / P_{1}^{*}\right)^{1 / 2}}+h_{2}} \\
& +P_{1}^{*} Q \frac{(-1 / 2) h_{1} h_{2} \theta_{1} P_{\min }^{1 / 2} P_{1}^{*-3 / 2} e^{\theta_{1}\left(P_{\min } / P_{1}^{*}\right)^{1 / 2}}}{\left(h_{1} e^{\theta_{1}\left(P_{\min } / P_{1}^{*}\right)^{1 / 2}}+h_{2}\right)^{2}}=0 .
\end{aligned}
$$

From Hypotheses 2 and 3 we know that as the freight price goes up, the utility value of this transportation mode decreases, so the probability $\operatorname{Pr}_{i}$ of the consignor who chooses this transportation mode will shrink; namely, $\partial \operatorname{Pr}_{i} / \partial P<0$. Therefore,

$$
\frac{(-1 / 2) h_{1} h_{2} \theta_{1} P_{\min }^{1 / 2} P^{-3 / 2} e^{\theta_{1}\left(P_{\min } / P\right)^{1 / 2}}}{\left(h_{1} e^{\theta_{1}\left(P_{\min } / P\right)^{1 / 2}}+h_{2}\right)^{2}}<0 .
$$

$$
h_{1}=e^{\theta_{2} F_{1}{ }^{1 / 2}}>0, h_{2}=\sum_{j=2}^{N} e^{\theta_{1}\left(P_{\min } / P_{j}\right)^{1 / 2}+\theta_{2} F_{j}^{1 / 2}}>0 \text { are }
$$
already known, so from inequation (19) we can come to the conclusion $\theta_{1}>0$. Equation (18) reaches the maximum value at point $P_{1}^{*}$. We apply $P_{1}^{*}$ to $(17)$, and $\theta_{1}>0$, so $(17)<0$. That is to say, (17) is monotonically decreasing at point $P_{1}^{*}$. Therefore, (17) reaches the maximum value $P_{1}$ before point $P_{1}^{*}$, so the inequality $P_{1}<P_{1}^{*}$ is proved (see Figure 2 ).

From the model analysis above we know that, because of the introduction of carbon saving profit coefficient, the railway freight income maximization model can change the saved carbon emission into enterprises' profits, strengthen their will of energy conservation and emission reduction, and encourage them to join in the carbon emission trade. At the same time, this model can accelerate the development of green low-carbon transportation, lower the railway freight fare, and guide the consignor to choose the resource-saving and environmental-friendly railway transportation. In this case, the share of railway freight in transportation channel will increase, the transportation structure can be optimized, and the resource-saving and environmental-friendly development road can be paved. 


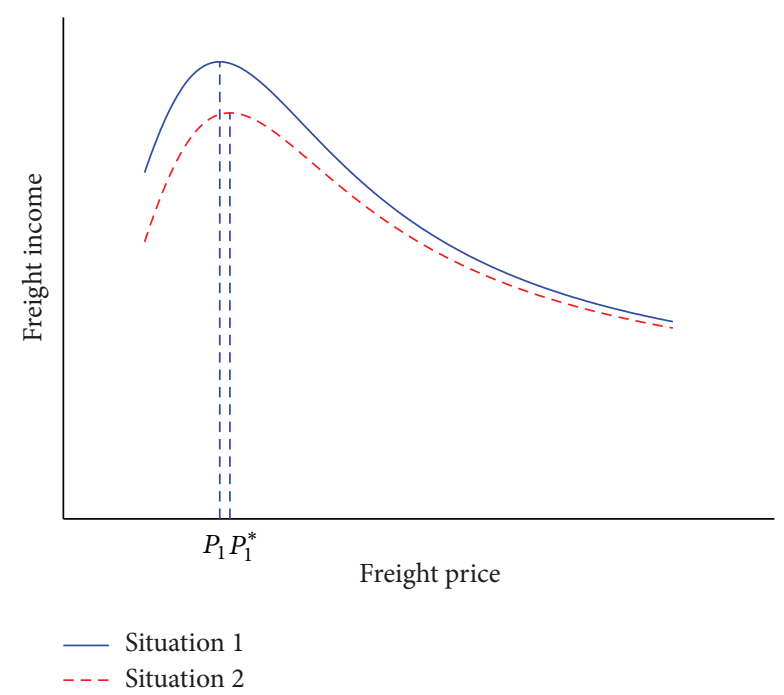

FIGURE 2: The relationship between railway freight income and freight price of two cases.

\section{Case Analysis}

The Opinions of the State Council on Reforming Railway Investment and Financing System and Accelerating Railway Construction proposed that the railway fare system should be improved, the reform of railway fare should be marketoriented, and the national railway freight fare should be decided by principle of keeping a reasonable balance between railway and the highway. It also proposed that a dynamic mechanism of adjusting the railway freight fare according to the highway freight fare should be established. Therefore, this paper assumes that, in a certain period of time, there are only railway freight and highway freight $(N=2)$ available to the consignor. Suppose that the service attribute value and highway freight fare are already known; this case will solve the railway freight income maximization model which is based on the low-carbon economy.

The service attribute value of transportation modes can be obtained from the market. Safety $S_{i}=(1-$ rate of damaged cargo), and the rates of damaged cargo of railway and highway are $5 \%$ and $2 \%$, respectively; punctuality $Z_{i}$ can be reflected by on-schedule rate which can be obtained from statistical data, and the on-schedule rate of railway and highway is 95\% and 97\%, respectively; convenience $C_{i}$ can be reflected by operation frequency of goods, efficiency of handling procedures and $24 \mathrm{~h}$ service, and so forth. We can designate this index with a number between 1 and 10, and the actual value can be obtained through survey and questionnaire [20]; timeliness $T_{i}$ can be reflected by average traveling speed. The average traveling speed of railway freight is $33.8 \mathrm{~km} / \mathrm{h}$ and of highway freight is $59.09 \mathrm{~km} / \mathrm{h}$ [21]. The attribute values of railway freight service and highway freight service are shown in Table 1.

The weight coefficient $\lambda_{i}(i=1,2,3,4)$ of every factor influencing the service level can be obtained through Fuzzy Comprehensive Evaluation, while the extent of different factors influencing the transportation mode can be determined
TABLE 1: Attribute values of railway freight and highway freight.

\begin{tabular}{lcccc}
\hline $\begin{array}{l}\text { Attribute value } \\
\text { of service }\end{array}$ & $S_{i}$ & $T_{i}$ & $C_{i}$ & $Z_{i}$ \\
\hline Railway & $95 \%$ & $33.8 \mathrm{~km} / \mathrm{h}$ & 5 & $95 \%$ \\
Highway & $98 \%$ & $59.09 \mathrm{~km} / \mathrm{h}$ & 10 & $97 \%$ \\
\hline
\end{tabular}

by surveying. Model parameters $\omega_{i}(i=1,2,3,4)$ can be calculated out of function (4) and (5). The sample value $K=$ 100 and $N=2$ are taken. With the help of the statistics in Table 2, we can build a logarithm likelihood function. Like (11), we calculate the partial derivative and solve the equation set; then we can get the maximum likelihood estimated value $\theta_{i}(i=1,2)$. The values of model parameters are shown in Table 3.

According to the statistical bulletin for transportation industry development of 2013, highway freight enterprises consume $1.9 \mathrm{~kg}$ standard coal per million $\mathrm{t} \cdot \mathrm{km}$. Since there is no specific data to describe the energy consumption of railway freight, this paper uses the calculation method stipulated in GB/T 2589-2008 general rule for calculating comprehensive energy consumption to calculate the energy consumption of railway freight. Namely, we convert the energy consumed in different transportation modes into the universal unit and then get the total amount of energy consumed in the freight. According to (20) and data from Tables 4 and 5 we can work out the total energy consumption of railway freight, which is 5.81621439 billion $\mathrm{kg}$ standard coal. Thus, we know that railway freight consumes $0.2 \mathrm{~kg}$ standard coal per hundred $\mathrm{t} \cdot \mathrm{km}$. Consider

$$
E=\left(A a \gamma_{1}+B b \gamma_{2}\right) Q
$$

In this function, $A$ represents oil consumption for $10^{4} \mathrm{t} \cdot \mathrm{km}(\mathrm{kg})$ of diesel locomotive. $B$ represents electricity consumption for $10^{4} \mathrm{t} \cdot \mathrm{km}(\mathrm{kw} \cdot \mathrm{h})$ of electric locomotive. $a$ and $b$ represent freight turnover proportion of diesel locomotive and electric locomotive, respectively, and $a+b=1$. $\gamma_{1}, \gamma_{2}$ represent reference coefficients of diesel and electricity, respectively. $Q$ represents the total freight turnover of railway.

According to the database of Intergovernmental Panel on Climate Change of United Nations (IPCC), the carbon emission volume per unit standard coal is $2.77 \mathrm{~kg}$. Therefore,

$$
\mathrm{Q}_{\mathrm{ECO}_{2}}=2.77 \mathrm{kgCO}_{2} / \mathrm{kgce} \text {. }
$$

At present, our country's carbon emission trade system is imperfect yet. The price varies from exchange to exchange. Therefore, this paper chooses the average trade price of Shenzhen carbon market which is relatively stable and has the highest trading volume as the carbon trade price. The statistics from Low-Carbon Industry Web show that, till Sept. 30, 2014, the total trading volume of Shenzhen carbon market is $1,698,369$ tons, the total volume of transaction is $114,941,918.94$ yuan, and the average trading price is 67.68 yuan/t. According to the concept of carbon saving profit defined in this paper, compared with a highway freight 
TABLE 2: Statistics of 2012 and 2013 for railway and highway.

\begin{tabular}{lcccc}
\hline \multirow{2}{*}{ Value } & \multicolumn{2}{c}{ Railway } & \multicolumn{2}{c}{ Highway } \\
& Freight turnover $\left(10^{8} \mathrm{t} \cdot \mathrm{km}\right)$ & Freight fare $(\mathrm{yuan} / \mathrm{t} \cdot \mathrm{km})$ & Freight turnover $\left(10^{8} \mathrm{t} \cdot \mathrm{km}\right)$ & Freight fare $(\mathrm{yuan} / \mathrm{t} \cdot \mathrm{km})$ \\
\hline 2012 & 29187.09 & 0.11 & 59534.86 & 0.40 \\
2013 & 29173.89 & 0.13 & 55738.08 & 0.49 \\
\hline
\end{tabular}

TABLE 3: Values of model parameters.

\begin{tabular}{lllllllllcc}
\hline Parameter & $\lambda_{1}$ & $\lambda_{2}$ & $\lambda_{3}$ & $\lambda_{4}$ & $\omega_{1}$ & $\omega_{2}$ & $\omega_{3}$ & $\omega_{4}$ & $\theta_{1}$ & $\theta_{2}$ \\
\hline Value & 0.1 & 0.4 & 0.4 & 0.1 & 1.02 & 0.017 & 0.1 & 1.03 & 4.97 & 14.64 \\
\hline
\end{tabular}

TABLE 4: Statistics for railway freight of 2012.

\begin{tabular}{|c|c|c|c|c|c|c|}
\hline \multirow[b]{2}{*}{ Item } & \multicolumn{3}{|c|}{ Diesel locomotive } & \multicolumn{3}{|c|}{ Electric locomotive } \\
\hline & $\begin{array}{l}\text { Proportion of } \\
\text { freight turnover } \\
\text { (\%) }\end{array}$ & $\begin{array}{l}\text { Freight turnover } \\
\qquad\left(10^{8} \mathrm{t} \cdot \mathrm{km}\right)\end{array}$ & $\begin{array}{c}\text { Oil } \\
\text { consumption for } \\
10^{4} \mathrm{t} \cdot \mathrm{km}(\mathrm{kg})\end{array}$ & $\begin{array}{l}\text { Proportion of } \\
\text { freight turnover } \\
\qquad(\%)\end{array}$ & $\begin{array}{l}\text { Freight turnover } \\
\qquad\left(10^{8} \mathrm{t} \cdot \mathrm{km}\right)\end{array}$ & $\begin{array}{c}\text { Electricity } \\
\text { consumption for } \\
10^{4} \mathrm{t} \cdot \mathrm{km}(\mathrm{kw} \cdot \mathrm{h})\end{array}$ \\
\hline Value & 27.9 & 8143.20 & 26.77 & 72.1 & 21043.90 & 102.07 \\
\hline
\end{tabular}

TABLE 5: Reference coefficient of converting other kinds of energy into standard coal.

\begin{tabular}{lc}
\hline Name of energy & Reference coefficient \\
\hline Diesel & $1.4571 \mathrm{kgce} / \mathrm{kg}$ \\
Electricity & $0.1229 \mathrm{kgce} /(\mathrm{kw} \cdot \mathrm{h})$ \\
\hline
\end{tabular}

Origin: GB/T 2589-2008 general rule for calculating comprehensive energy consumption.

enterprise, the carbon saving profit one railway freight enterprise can earn from per $\mathrm{t} \cdot \mathrm{km}$ cargo is

$$
P_{c}=\frac{(1.9-0.2)}{100} \times \frac{2.77}{1000} \times 67.78=0.0032 \text { yuan }
$$

Our country's highway freight price is 0.49 yuan $/ \mathrm{t} \cdot \mathrm{km}$, and the total ration volume of railway and highway transport in 2013 is 8491.197 billion $\mathrm{t} \cdot \mathrm{km}$. Since the railway transportation cost is lower than that of highway and the current railway freight service in terms of convenience and flexibility is generally inferior to that of highway, this paper takes that railway freight rate is lower than the highway freight rate. Through MATLAB processing, we can solve the railway freight income maximization model under two different conditions. Namely, we take the carbon saving profit into consideration and leave out the carbon saving profit. The results are as follows.

If we take the carbon saving profit into consideration, the railway freight price is $P_{1}=0.1528$, the market share of railway freight is $29.42 \%$, and the total income of railway freight is 389.705 billion yuan.

Otherwise, the railway freight price is $P_{1}^{*}=0.1563$, the market share of railway freight is $28.76 \%$, and the total income of railway freight is 381.695 billion yuan.

From the above comparison, we can easily find that, with the introduction of carbon saving profit, the railway freight price decreases, while the total income of railway freight increases by 8.01 billion yuan, and the market share also increases by $2.3 \%$.

\section{Conclusion}

Government cares more about the environmental issues due to transportation pollutant emissions, particularly in an era of climate change and global warming. However, the transport enterprises care more about revenue and profit, and consignors care more about price and service quality of transport. In order to consider the concerns of these different stakeholders simultaneously, this paper defines the concept of carbon saving profit and establishes income maximization model of railway freight. The income maximization model of railway freight based on low-carbon economy has been validated to be effective and reasonable through case analysis. The conclusion can be summarized as follows:

(1) The model can scientifically guide the consignors who prefer to use resource-saving and environmentalfriendly transportation modes, which is in conformity with the interests of government. With the introduction of carbon saving profit, the railway freight price decreases, while the market share increases.

(2) Income maximization model takes account of enterprises interests and gives full play to railway advantage in carbon competition. Participation in carbon trading is not only to promote energy conservation and emission reduction, but also to increase the railway transport enterprises' income.

(3) The sharing ratio model of transportation modes is established based on the principle of utility maximization which gives consideration to both price and quality of service. The application of the maximum likelihood method makes the model better meet the actual conditions.

\section{Competing Interests}

The authors declare that they have no competing interests. 


\section{Acknowledgments}

This research is supported by the Science and Technology Research Development Program of China Railway (Grant no. 2015F024).

\section{References}

[1] International Energy Agency (IEA), $\mathrm{CO}_{2}$ Emissions from Fuel Combustion Highlights, International Energy Agency (IEA), Paris, France, 2014, http://www.iea.org/t\&c/termsandconditions/.

[2] G. Xu, "Study on price model of railway freight transport market," China Railway Science, vol. 24, no. 1, pp. 129-131, 2003.

[3] F. Feng and Q. Zhang, "Multimodal transport system coevolution model based on synergetic theory," Discrete Dynamics in Nature and Society, vol. 2015, Article ID 108926, 10 pages, 2015.

[4] D. He and Y. Guo, "Research on pricing model of transport competition countermeasure," Journal of Southwest Jiaotong University, vol. 35, no. 5, pp. 539-542, 2000.

[5] K.-M. Chen and X.-Q. Luo, "Game-theory of reasonable ticket price for urban railway transport," Journal of Chang'an University (Natural Science Edition), vol. 25, no. 4, pp. 52-55, 2005.

[6] F. Feng, Z. Tang, and L. Wang, "A fault tolerance optimization model of the China Railway geographic network topological structure," Discrete Dynamics in Nature and Society, vol. 2015, Article ID 871074, 8 pages, 2015.

[7] J. Chi and J. Baek, "Price and income elasticities of demand for air transportation: empirical evidence from US airfreight industry," Journal of Air Transport Management, vol. 20, pp. 1819,2012

[8] N. Shah and J. K. Brueckner, "Price and frequency competition in freight transportation," Transportation Research Part A: Policy and Practice, vol. 46, no. 6, pp. 938-953, 2012.

[9] A. Samimi, K. Kawamura, and A. Mohammadian, "A behavioral analysis of freight mode choice decisions," Transportation Planning and Technology, vol. 34, no. 8, pp. 857-869, 2011.

[10] K. Cullinane and N. Toy, "Identifying influential attributes in freight route/mode choice decisions: a content analysis," Transportation Research Part E: Logistics and Transportation Review, vol. 36, no. 1, pp. 41-53, 2000.

[11] W. Wang, W. Zhang, H. Guo, H. Bubb, and K. Ikeuchi, "A safety-based approaching behavioural model with various driving characteristics," Transportation Research C: Emerging Technologies, vol. 19, no. 6, pp. 1202-1214, 2011.

[12] W. Wang, H. Guo, Z. Gao, and H. Bubb, "Individual differences of pedestrian behaviour in midblock crosswalk and intersection," International Journal of Crashworthiness, vol. 16, no. 1, pp. 1-9, 2011.

[13] G. E. Cantarella and S. de Luca, "Multilayer feedforward networks for transportation mode choice analysis: an analysis and a comparison with random utility models," Transportation Research Part C: Emerging Technologies, vol. 13, no. 2, pp. 121155, 2005.

[14] J. Rich, P. M. Holmblad, and C. O. Hansen, "A weighted logit freight mode-choice model," Transportation Research Part E: Logistics and Transportation Review, vol. 45, no. 6, pp. 10061019, 2009.

[15] X. Sun, H. Lu, and W. Chu, "A low-carbon-based bilevel optimization model for public transit network," Mathematical Problems in Engineering, vol. 2013, Article ID 374826, 6 pages, 2013.
[16] L. Lu, C. Wang, W. Deng, and X. Bing, "An optimal allocation model of public transit mode proportion for the low-carbon transportation," Mathematical Problems in Engineering, vol. 2015, Article ID 390606, 8 pages, 2015.

[17] Y. Yin, Z.-C. Li, W. H. K. Lam, and K. Choi, "Sustainable toll pricing and capacity investment in a congested road network: a goal programming approach," Journal of Transportation Engineering, vol. 140, no. 12, Article ID 04014062, 2014.

[18] C.-C. Chao, "Assessment of carbon emission costs for air cargo transportation," Transportation Research Part D: Transport and Environment, vol. 33, pp. 186-195, 2014.

[19] Q. Yang and E.-C. Xi, "Quantification research on externality of freeway," China Journal of Highway and Transport, vol. 19, no. 5, pp. 102-107, 2006.

[20] F.-L. Feng and L.-L. Xiong, "Railway high-end freight product positioning model based on co-benefits," in Proceedings of the 14th COTA International Conference of Transportation Professionals: Safe, Smart, and Sustainable Multimodal Transportation Systems (CICTP '14), pp. 1661-1673, ASCE, Changsha, China, July 2014.

[21] H. Qin, Comparative study of freeway transportation in China and United States [Ph.D. thesis], Chang'an University, Xi'an, China, 2011. 


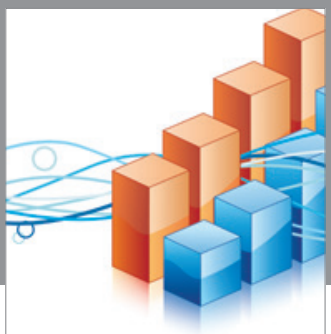

Advances in

Operations Research

vatem alat4

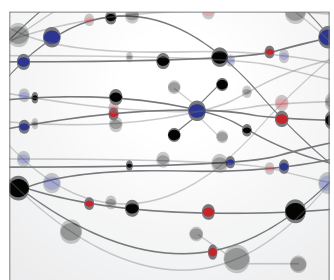

\section{The Scientific} World Journal
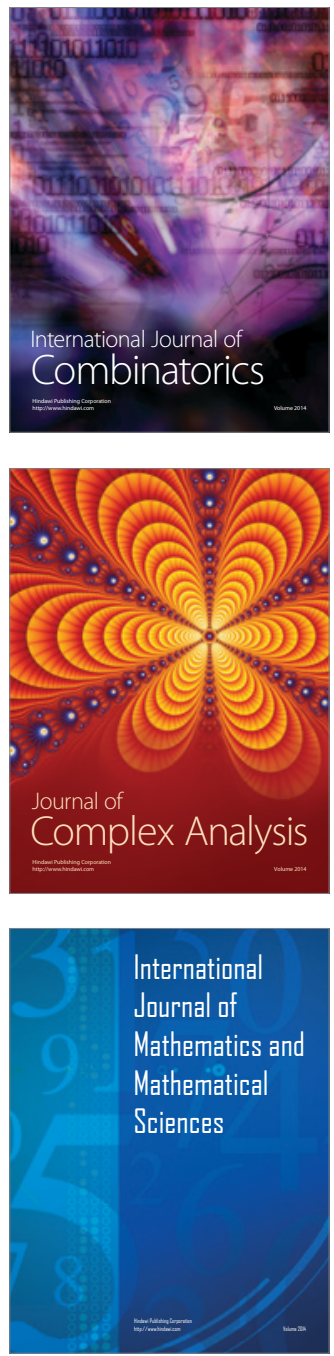
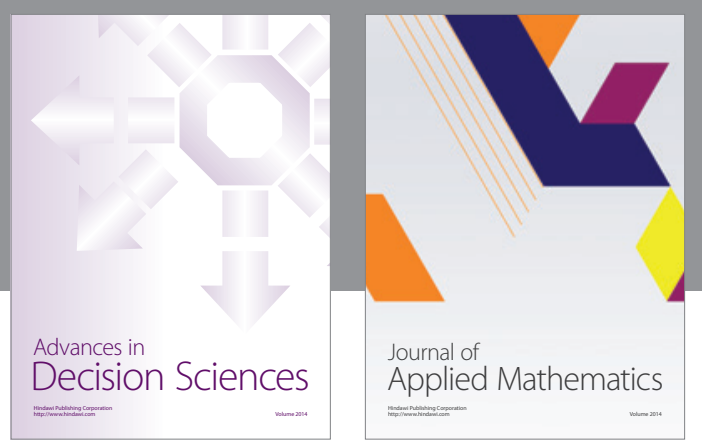

Algebra

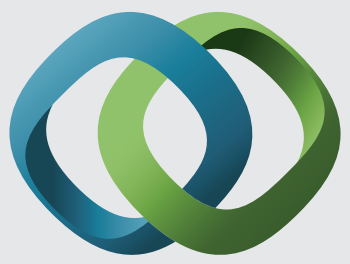

\section{Hindawi}

Submit your manuscripts at

http://www.hindawi.com
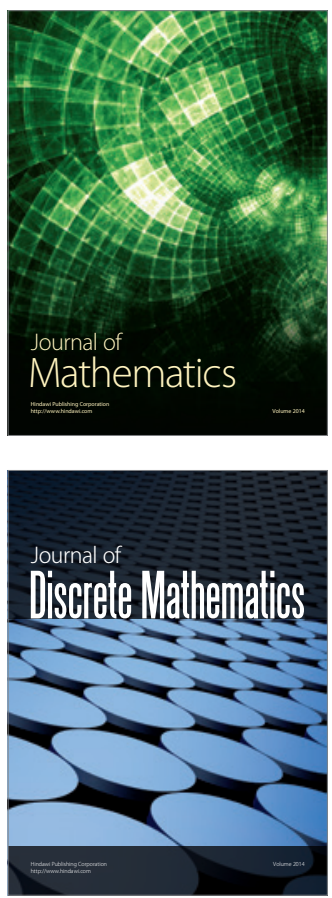

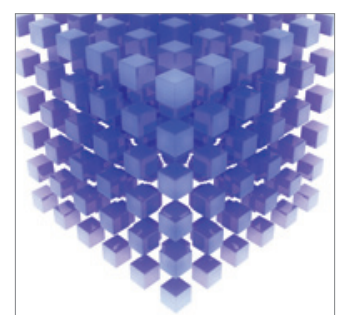

Mathematical Problems in Engineering
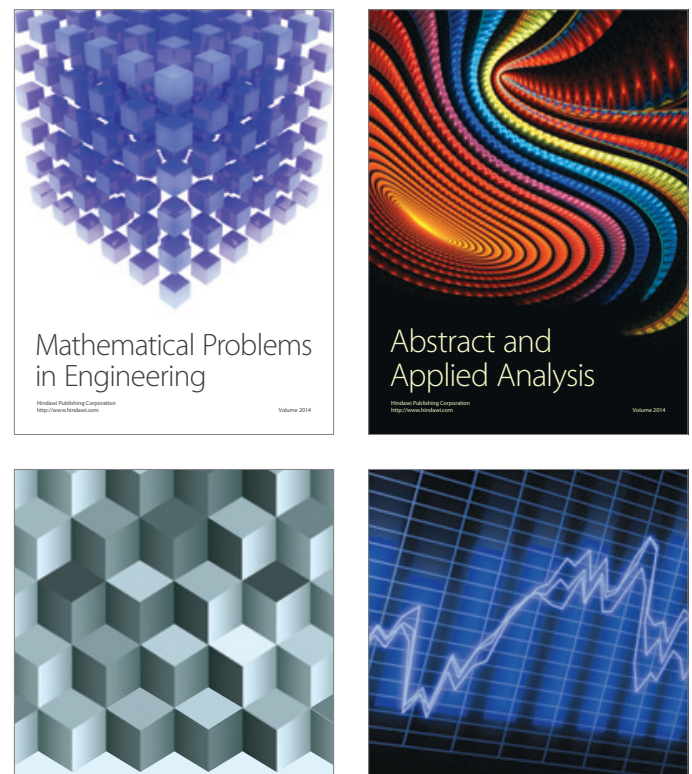

Journal of

Function Spaces

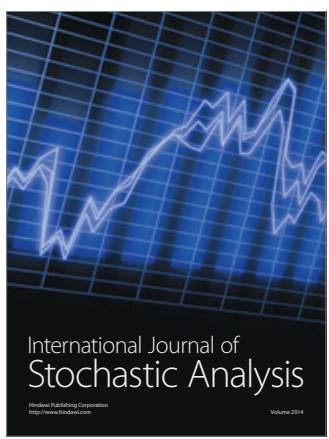

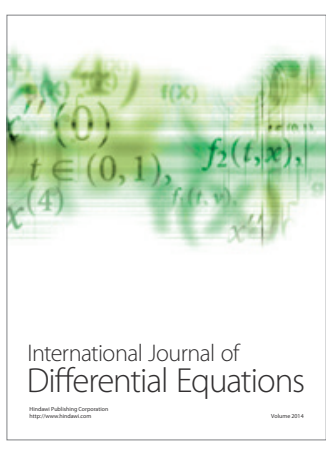
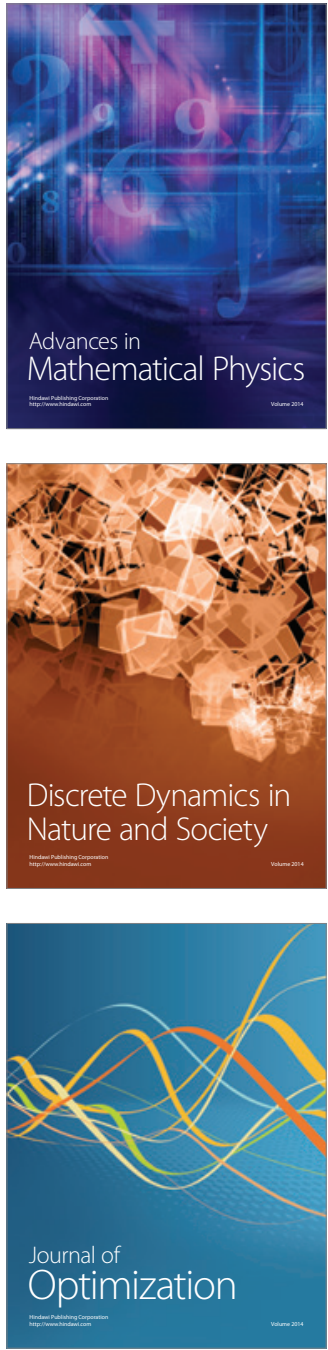